\title{
Limitations on the word superiority effect with a fixed target set
}

\author{
SETH N. GREENBERG \\ Union College, Schenectady, New York 12308 \\ and \\ LESTER E. KRUEGER \\ Ohio State University, Columbus, Ohio 43210
}

\begin{abstract}
Failure to achieve a word superiority effect has been attributed to the use of the fixed target set (Massaro, 1973). Present results indicated that several procedures other than the fixed set inhibit word superiority. Specifically, when a subject was not forced or encouraged to attend to a total stimulus item, word superiority was lost. Other recent findings can be interpreted within the framework of this attention notion.
\end{abstract}

With a fixed target set, Massaro (1973) and Thompson and Massaro (1973, Experiment 2) failed to find better letter identification in words than in nonwords (word superiority effect). More recent research has indicated such an effect is possible (Carr, Lehmkuhle, Kottas, Astor-Stetson, \& Arnold, 1976; Krueger \& Weiss, 1976; Spector \& Purcell, 1977). An analysis of Massaro's work suggested that his failure to achieve word superiority, when others have succeeded, may have resulted from a cabal of procedures and not simply the use of a fixed target set. Since Massaro's work stands as major testimony against word superiority, a thorough investigation of the inhibiting effects of all his procedures is warranted.

The procedures postulated to have reduced the opportunity for word superiority included: use of a fixed target set, use of a fixed target position, a mixed presentation of words and nonwords, and use of target letters that were physically distinct from other letters in the stimuli. First, let us consider the restriction of the target location to the middle position in threeletter displays. Smith and Spoehr (1974) argued that any procedure that allowed the subject to know the target position in advance would lead to a single-position strategy in which other information in the stimuli would be ignored, that is, higher order relationships. Johnston and McClelland (1974) found word superiority only if the subject attended to an entire display when a varying target set was used. To test the importance of the way attention is allocated, with a fixed set, a group allowed to attend to a single position was compared with a group required to attend to the entire stimulus.

The research was supported in part by funds obtained from the Ohio University Research Council. The authors wish to acknowledge the assistance of Jan Johnson in preparing and executing this research. The authors also wish to thank Becky Lumpkin for preparing the manuscript. Reprint requests may be sent to Seth Greenberg, Department of Psychology, Union College, Schenectady, New York 12308.
The group allowed to attend to a single position was the replication group. This group operated under basically the same conditions used by Massaro (1973). The second group, the word-view group, differed from the first group only in that it performed a subsidiary word judgment task in addition to the letter identification task. The subsidiary task required the subject to attend to the entire stimulus (view the whole word). If word superiority were found with the word-view group, but not with the replication group, this would indicate that one critical feature of Massaro's procedure was his failure to encourage subjects to attend to the entire stimulus.

A second procedure investigated Massaro's (1973) mixed presentation of words and nonwords. Aderman and Smith (1971) argued that the effect of word familiarity depended upon the subject's anticipating word presentations. This is impossible with mixed presentations but very likely with blocked presentations. Carr et al. (1976) appeared to show that a blocked design was necessary for word superiority. However, Carr et al. changed several of Massaro's conditions (e.g., smaller visual angles were subtended by the stimuli, and target positions were randomly tested) so the precise contribution of blocking could not be assessed. The present study compared a group receiving a mixed presentation, the replication groups, with a group receiving a blocked presentation, the word-block group. The two groups differed only on blocked vs. mixed presentation, so the contribution of presentation procedure could be fairly assessed.

A third concern was Massaro's (1973) target set. Letters in the target set were easily distinguished from the nontarget letters shown. Smith and Spoehr (1974) contended that letter perceptibility was a product of the context in which the letter was embedded and the letter's similarity to surrounding letters. Lack of visual confusion between target and nontargets may have 
made the targets in Massaro's study particularly distinctive. Consequently, the effect of context may have been reduced. To test this factor, target-nontarget similarity was systematically varied. If this factor was important, then even the replication group might exhibit word superiority when target-nontarget similarity was strong.

If any of the above changes in condition fail to produce a word superiority effect, Massaro's (1973) conclusion that prior knowledge of targets eliminates word superiority effects would gain support.

\section{METHOD}

\section{Apparatus}

The basic projection equipment included a Kodak RA950 projector with a Gerbrands G1166 electronic shutter and a Kodak 800 Carousel projector with a blade shutter. Both projectors were controlled by a Psionix 124A timer.

\section{Design and Stimuli}

Stimulus strings were 24 three-letter words and 24 nonwords containing a target letter $\mathrm{R}$ or $\mathrm{P}$ in block type (Prestype Total-2 Pica 2065). Nonwords were created by replacing $A$, present in each word, with a visually similar B. Half of the words and nonwords contained nontarget letters printed in block type, so the nontarget and target letters were confusable; the other half contained nontarget letters in curved type (Tarco $\mathrm{N}$ Letter Set, Type $400 \mathrm{CL}, 10 \mathrm{~mm}$ ), so target letters would be distinctively different. Stimuli were constructed so that, for each factorial combination of confusion (i.e., confusable vs. distinct) and context (i.e., word vs. nonword), each serial position contained a target equally often (see Table 1). Each three-letter string subtended a visual angle of $2.8 \mathrm{deg}$.

Target position was either blocked by session (position certain) and counterbalanced across sessions or randomized within a session (position uncertain), with each position tested equally often within the session. The target position certainty variable was factorially combined with confusability and context.

\section{Procedure}

There were four sessions. The first session determined the $80 \%$ recognition exposure duration for each subject, using a modified staircase method (Reicher, 1969). Strings in this session were the letters $R$ and $P$ flanked on each side by a letterlike random form. Stimulus durations resulting in $80 \%$ recognition ranged from 58 to $92 \mathrm{msec}$.

The next three sessions were experimental sessions, each divided into two 60 -trial blocks with 6 practice trials preceding each block. Stimuli consisted of the words and nonwords described previously. The subject sat 27 in. from a translucent screen and focused on the center of a box outlined in black. Following the stimulus, a mask (broken, straight, and curved lines) appeared for $3 \mathrm{sec}$ in the space previously occupied by the stimulus. The subject first pressed an $\mathrm{R}$ or $\mathrm{P}$ button and then a word or nonword button, if required.

\section{Subjects}

Thirty-six Ohio University students received extra credit for

Table 1

Examples of P and R Stimuli Employed

\begin{tabular}{llc}
\hline \multirow{2}{*}{$\begin{array}{c}\text { Target } \\
\text { Position }\end{array}$} & \multicolumn{2}{c}{ Context } \\
\cline { 2 - 3 } & Word & Nonword \\
\hline First & RAN \& PAN & RBN \& PBN \\
Middle & ART \& APT & BRT \& BPT \\
Last & CAR \& CAP & CBR \& CBP \\
\hline
\end{tabular}

participating. Twelve students were assigned to each of the three groups: (1) replication group, which replicated Massaro's (1973) conditions; (2) word-view group, which performed a word judgment task (i.e., decide whether a word or nonword had been presented) in addition to the primary letter identification task; and (3) word-block group, which received blocked presentations of words and nonwords. Half of the subjects in the word-block and word-view groups knew what the target position would be on each trial (position certain), and half did not (position uncertain).

\section{RESULTS}

Data from the replication group confirmed that, under the conditions used by Massaro (1973), a word superiority effect is not obtained. No significant main effects or interaction were observed.

Data from the letter identification task for the wordview group revealed a significant position effect, Position by Context interaction, and Position by Context by Confusion interaction (all ps $<.05$ ). The first position was perceived best, and the middle position worst (see Table 2). The two-way interaction indicated that letter identification was best in words (vs. nonwords) when the tested letters appeared in the first position. Further, the three-way interaction and subsequent Newman-Keuls test indicated that the perceptual advantage for first-position letters in words was only obtained when the target letter was distinctly different from nontarget letters (distinct condition). The word superiority effect with distinct first-position targets was exhibited by both word-view position-certain and position-uncertain subjects (see Table 2). A comparison of position-certain word-view subjects and replication subjects, who were all position certain, indicated a significantly stronger word superiority effect for the word-view group than for the replication group $(p<.01)$ in the distinct first-position test condition.

Subsidiary task performance for the word-view group revealed an effect of confusion $(\mathrm{p}<.01)$, position $(\mathrm{p}<.01)$, and a Context by Confusion by Position interaction $(p<.05)$. It was easiest to make correct word vs. nonword judgments when target letters were distinct and when the target appeared in the first position (see Table 3). The interaction signified that word vs. nonword judgments were particularly easy when targets were distinct and located in the first position.

Data from the word-block group indicated significant effects of context $(p<.05)$, confusion $(p<.01)$, and an interaction of Confusion by Context by Position $(p<.01)$. Letter perception was better in words than in nonwords and better when targets were distinct rather than confusable. The three-way interaction again indicated that distinct first-position targets were perceived better in words than in nonwords; this was true for both position-certain and position-uncertain subjects. As with the word-view subjects, word-block positioncertain subjects exhibited a significantly stronger word superiority effect than did the replication subjects $(\mathrm{p}<.05)$ in the distinct first-position test condition.

Other examples of word superiority were found with 
Table 2

Percentage of Incorrect Letter Identification as a Function of Context, Confusability, Position, and Test Group

\begin{tabular}{|c|c|c|c|c|}
\hline \multirow[b]{2}{*}{ Group } & \multicolumn{2}{|c|}{ Confusable } & \multicolumn{2}{|c|}{ Distinct } \\
\hline & Word & Nonword & Word & Nonword \\
\hline & \multicolumn{4}{|c|}{ Replication Group, Position Certain } \\
\hline 1 & 27 & 25 & 21 & 24 \\
\hline 2 & 29 & 29 & 27 & 25 \\
\hline 3 & 30 & 31 & 26 & 27 \\
\hline \multirow[t]{2}{*}{ All } & 29 & 28 & 25 & 25 \\
\hline & \multicolumn{4}{|c|}{ Word-View Group, Position Certain } \\
\hline 1 & 29 & 25 & 14 & 28 \\
\hline 2 & 34 & 37 & 35 & 34 \\
\hline 3 & 30 & 34 & 23 & 26 \\
\hline \multirow[t]{2}{*}{ All } & 31 & 32 & 24 & 29 \\
\hline & \multicolumn{4}{|c|}{ Word-Block Group, Position Certain } \\
\hline 1 & 23 & 23 & 15 & 27 \\
\hline 2 & 22 & 20 & 18 & 17 \\
\hline 3 & 28 & 25 & 14 & 15 \\
\hline \multirow[t]{2}{*}{ All } & 25 & 23 & 16 & 20 \\
\hline & \multicolumn{4}{|c|}{ Word-View Group, Position Uncertain } \\
\hline 1 & 25 & 30 & 16 & 27 \\
\hline 2 & 29 & 34 & 32 & 25 \\
\hline 3 & 30 & 21 & 17 & 24 \\
\hline \multirow[t]{2}{*}{ All } & 28 & 28 & 22 & 25 \\
\hline & \multicolumn{4}{|c|}{ Word-Block Group, Position Uncertain } \\
\hline 1 & 25 & 21 & 13 & 27 \\
\hline 2 & 26 & 31 & 25 & 23 \\
\hline 3 & 30 & 43 & 18 & 30 \\
\hline All & 27 & 31 & 19 & 27 \\
\hline
\end{tabular}

Table 3

Percentage of Incorrect Context Judgments as a Function of Context, Confusability, Position, and Test Group

\begin{tabular}{lccccc} 
& \multicolumn{2}{c}{ Confusable } & & \multicolumn{2}{c}{ Distinct } \\
\cline { 3 - 5 } Group & Word & Nonword & & Word & Nonword \\
\hline & \multicolumn{3}{c}{ Word-View Group, Position Certain } \\
1 & 35 & 26 & 19 & 27 \\
2 & 33 & 41 & 22 & 33 \\
3 & 28 & 47 & 30 & 34 \\
All & 32 & 38 & 23 & 31 \\
& \multicolumn{4}{c}{ Word-View Group, Position } & Uncertain \\
1 & 23 & 30 & 13 & 31 \\
2 & 35 & 46 & 20 & 30 \\
3 & 43 & 47 & 32 & 29 \\
All & 34 & 41 & 22 & 30 \\
\hline
\end{tabular}

the word-block group. Position-uncertain subjects demonstrated word superiority with distinct and confusable targets appearing in the third position $(p<.05)$. The word superiority effect with confusable thirdposition target letters exhibited by the word-block group was significantly stronger than the effect exhibited by the word-view group $(\mathrm{p}<.01)$.

\section{DISCUSSION}

Contrary to Massaro (1973) and Thompson and Massaro (1973), the present study found word superiority even when a fixed target was used. Comparisons between the replication group and the word-view and word-block groups indicated that conditions other than a fixed target set had inhibited word superiority in Massaro's case.

First, Massaro (1973) informed subjects in advance of the target's position. Advance knowledge of the position, as the performance by the word-view subjects indicated, did not directly eliminate the word superiority effect. Rather, it was the consequence of this advance knowledge, that is, single-minded attention to the target's position, that eliminated the word superiority effect. Had Massaro's subjects been required to consider the entire stimulus, letter combinations would have been processed and word superiority would have resulted as in the present study (word-view group). The key factor, then, was that Massaro failed to encourage subjects to attend to the entire stimulus.

Attention to an entire display is not sufficient for a word superiority effect. Estes (1975) randomly tested positions to encourage subjects to look at entire words and found no word superiority effect. However, similarity of the letters in the target set may play an important role. Thompson and Massaro (1973) demonstrated that similarity of alternatives affects performance when fixed target sets are used. Estes used two easily distinguished letters (L and R), whereas the present study used similar letters (P and $\mathrm{R})$.

Second, the word-block vs. replication comparison indicated that the blocked presentation produces a larger familiarity effect than does the mixed presentation, which Massaro (1973) used. Comparisons of the word-block and word-view groups suggested that being able to anticipate words, as a consequence of the blocked presentation, enabled better use of word familiarity than did being forced to attend to the entire stimulus. Thus, anticipation of words encouraged subjects to do more than attend to the entire stimulus.

Massaro's (1973) choice of the middle position as the target position also made word superiority difficult to obtain. The present results confirmed the Carr et al. (1976) finding that word superiority is least likely to occur when the target occupies the middle position in a three-letter word. Even when conditions allowed superiority effects for the peripheral positions, little or no effect was obtained in the middle position. However, it should be noted that tests of peripheral positions also failed to produce word superiority effects under a combination of conditions hypothesized to be inhibiting the word effect (i.e., the replication group). Thus target position was not the only limiting factor.

Finally, the confusion factor produced an unexpected outcome. Letter identification was aided more by word familiarity when the target was distinct from nontarget letters. Word judgments also were easiest when target letters were distinct. It follows that word familiarity ought to aide letter identification the most when "wordness" was easiest to judge, since a speedy determination of "wordness" enhances the opportunity for a word superiority effect. Further, word superiority with distinct targets indicated that visual distinctiveness did not isolate the target letter from the rest of the display.

With the exception of the confusion factor, Massaro's (1973) conditions were found to inhibit word superiority. Yet Purcell, Stanovich, and Spector (1978) demonstrated word superiority with Massaro's conditions. Purcell et al. found that the visual angle subtended by the letter string was critical. A visual angle of $.53 \mathrm{deg}$ was used by Purcell et al. (Experiment 2), whereas Massaro used an angle of $3.33 \mathrm{deg}$. An attempt to replicate the word superiority effect with Massaro's conditions and an angle of $2.11 \mathrm{deg}$ failed. Purcell et al. concluded that large angles, in excess of $1 \mathrm{deg}$ prevented the higher order units from being processed, so word familiarity had no effect.

The present study obtained word superiority effects even with stimuli subtending a relatively large visual angle of $2.8 \mathrm{deg}$, but not when Massaro's (1973) conditions were replicated. it would seem, then, that visual angle is critical when conditions 
otherwise encourage subjects to focus on a single target position (i.e., the replication group) rather than on the whole word (i.e., word-view and word-block groups). When attention was paid to a single position (Purcell et al., 1978, Experiment 2), the small visual angle may have led to inadvertent processing of nontarget letters and thus to whole word processing. Together, the findings of Purcell et al. and this study indicate that the critical factor for obtaining a word superiority effect is to get the subject to process the whole word. This can be accomplished either by physical constraints (a small visual angle) or by higher level prodding (e.g., a word judgment task).

\section{REFERENCES}

Aderman, D., \& Smith, E. E. Expectancy as a determinant of functional units in perceptual recognition. Cognitive Psychology, 1971, 2, 117-129.

Carr, T. H., Lehmkuhle, S. W., Kottas, B., Astor-Stetson, E. C., \& ARnold, D. Target position and practice in the identification of letters in varying contexts: A word superiority effect. Perception \& Psychophysics, 1976, 19, 412-416.

Estes, W. K. The locus of inferential and perceptual processes in letter identification. Journal of Experimental Psychology: General, 1975, 104, 122-145.

Johnston, J. C., \& McClelland, J. L. Perception of letters in words: Seek and ye shall not find. Science, 1974, 184, 11921193.

KRUEGER, L. E., \& Weiss, M. E. Letter search through words and nonwords: The effect of fixed, absent, or mutilated targets. Memory \& Cognition, 1976, 4, 200-206.

Massaro, D. W. Perception of letters, words, and nonwords. Journal of Experimental Psychology, 1973, 100, 349-353.

Purcell, D. E., Stanovich, K. E., \& Spector, A. Visual angle and the word superiority effect. Memory \& Cognition, 1978, 6, 308.

REICHER, G. M. Perceptual recognition as a function of meaningfulness of stimulus materials. Journal of Experimental Psychology, 1969, 81, 275-280.

Smith, E. E., \& Spoenr, K. T. The perception of printed English: A theoretical perspective. In B. H. Kantowitz (Ed.), Human information processing: Tutorials in performance and cognition. Potomac, Md: Erlbaum, 1974.

Spector, A., \& Purcell, D. E. The word superiority effect: A comparison between restricted and unrestricted alternative set. Perception \& Psychophysics, 1977, 21, 323-328.

Thompson, M. S., \& Massaro, D. W. Visual information redundancy in reading. Journal of Experimental Psychology, 1973, 98, 49-54.

(Received for publication October 22, 1979.) 